THOMPSON, D. M. Escape from $S^{D}$ associated with fixed-ratio reinforcement. Journal of the Experimental Analysis of Behavior, 1964, 7, 1-8.

THOMPSON, D. M. Time-out from fixed-ratio reinforcement: A systematic replication. Psychonomic Science, 1965, 2, 109-110.

ZIMMERMAN, J., \& FERSTER, D. B. Somc notes on timeout from reinforcement. Journal of the Experimental Analysis of Behavior, $1964,7,13-19$.

NOTE

1. This research was supported in part by PHS Research Grant No. 5R01 MH13343 from the National Institute of Mental Health.

\title{
Foot-thumping in the gerbil: The effect of establishing a home cage ${ }^{1}$
}

\begin{abstract}
CHRIS SPATZ ${ }^{2}$ and WILLIAM R. GRANGER, ${ }^{3}$ The University of the South, Sewanee, Tenn. 37375
\end{abstract}

In experiments with gerbils (Meriones unguiculatus) it was shown that length of home cage residence affects the probability of foot-thumping and that foot-thumping is significantly reduced in another gerbil's vacant home cage. General excitement or arousal seems to be the factor common to the situations in which gerbils foot-thump. Two possible functional interpretations were suggested.

Gerbils (Meriones unguiculatus) foot-thump by rhythmically hitting both hind feet against the floor simultaneously. The thumps are usually grouped by twos although there are occasional bursts of three or more. Gerbils foot-thump in a variety of situations, e.g., during sexual intercourse (Kuehn \& Zucker, 1968) and when shocked on the feet or given rewarding brain stimulation (Routtenberg \& Kramis, 1967; Kramis \& Routtenberg, 1969). We have found that gerbils foot-thump after being handled and dropped back into their home cage. During incidental observations, it was noted that gerbils did not foot-thump when dropped into a fresh cage. It was the purpose of these experiments to determine the relation of foot-thumping to the length of home cage residence.

\section{Experiment 1}

Subjects

The Ss were 12 adult male gerbils, about 4 months old, which were housed in $17.5 \times 24.5 \times 16 \mathrm{~cm}$ laboratory cages. The covers were hardware cloth and the plywood floors were covered with wood shavings. Food and water were available ad lib.

$$
\text { Design }
$$

Six periods of home cage residence were used: 0,20 , and $60 \mathrm{~min}$ and 24,48 , and $168 \mathrm{~h}$. Each $\mathrm{S}$ was tested in all six conditions. Two 6 by 6 Latin squares were used to determine the order of the conditions in which Ss served. No $S$ ever lived in the same cage twice. Ss were not tested more than once in a single day. Testing started at noon each day.

\section{Procedure}

An $S$ was placed into a cage with fresh wood shavings and was not disturbed for the prescribed period of home cage residence. At the end of the period, $S$ was picked up, stroked on the back for $15 \mathrm{sec}$, and dropped $18 \mathrm{~cm}$ ( 7 in.) back into the cage and observed for $2 \mathrm{~min}$. Latency and duration of any foot-thumping were recorded.

\section{Results}

The number of Ss that foot-thumped for each length of home cage residence is shown in Fig. 1. The greater the length of home cage residence, the greater the probability of foot-thumping. A Subjects/Groups by Repeated Measures analysis of variance on the duration scores, including zeros, produced a length of residence main effect that was significant $[F(5,30)=3.83, \quad p<.01]$. Neither the order of testing main effect or the interaction was significant. The mean duration of a foot-thumping session was $5.9 \mathrm{sec}, \mathrm{SD}=5.2 \mathrm{sec}$. The latency measures showed no systematic trend. The mean latency over all conditions was $3.1 \mathrm{sec}$, $\mathrm{SD}=2.6 \mathrm{sec}$.

\section{Experiment 2}

Experiment 2 was designed to assess the effect of daily handling and to replicate the procedures of Experiment 1.

Subjects and Procedures

Twelve adult male gerbils, about 7 months old, served as Ss. The conditions of housing, food and water supply, handling, and the $E$ were the same as in Experiment 1 .

\section{Design}

Experiment 2 extended over 13 days. All the Ss were tested on Day 1 in fresh cages. Ss 1.6 were then tested every day for 6 more days. Ss 7-12 were not handled during this period. On Day 7, all Ss were tested. On Day 8 , all Ss were tested in a fresh cage. Ss 7-12 were then tested every day for 7 more days, at which time all Ss were again tested. Thus, each $S$ served in the daily handled condition and the weekly handled condition. Again, testing started at noon.

\section{Results}

The main results for Experiment 2 are summarized in Table 1. A dependent-measures $t$ test comparing the duration scores after 1 week of daily handling or weekly handling was not significant, $\mathrm{t}, 11 \mathrm{df}=1.00, \mathrm{p}>.15$. There appear to be no systematic effects of handling on foot-thumping. The main difference between the results of Experiment 1 and Experiment 2 is that fewer Ss foot-thumped in the second experiment. However, as in Experiment 1, the greater the length of home cage residence, the greater the probability of foot-thumping.

\section{DISCUSSION}

General excitement or arousal seems to be the factor common to the diverse situations in which gerbils foot-thump. The present data are most simply explained by assuming that stroking and dropping produce sufficient excitement, but that a novel environment evokes responses incompatible with foot-thumping, e.g., responses connected with exploration.

As for functional significance, foot-thumping may serve as territorial behavior, as gerbils foot-thump in their home environments. In order to be sure that foot-thumping is related to home cage residence, it is necessary to show that the gerbils in Experiments 1 and 2 were responding to cues specific to their own cage and not to cues associated with any gerbil's cage. If the gerbils were responding to cues specific to their own cage, they should not foot-thump when dropped into the vacant cage of another gerbil. In order to test this, a preliminary experiment was

Table 1

Number of Gerbils that Foot-Thumped in Experiment 2

\begin{tabular}{|c|c|c|}
\hline & \multicolumn{2}{|c|}{$\begin{array}{c}\text { Length of } \\
\text { Cage Residence }\end{array}$} \\
\hline & $0 \mathrm{Min}$ & 1 Week \\
\hline $\begin{array}{l}\text { Daily Handling } \\
\text { and Testing } \\
\mathrm{N}=24\end{array}$ & 0 & 7 \\
\hline $\begin{array}{l}\text { Weckly Handling } \\
\text { and Testing } \\
N=24\end{array}$ & 1 & 9 \\
\hline
\end{tabular}




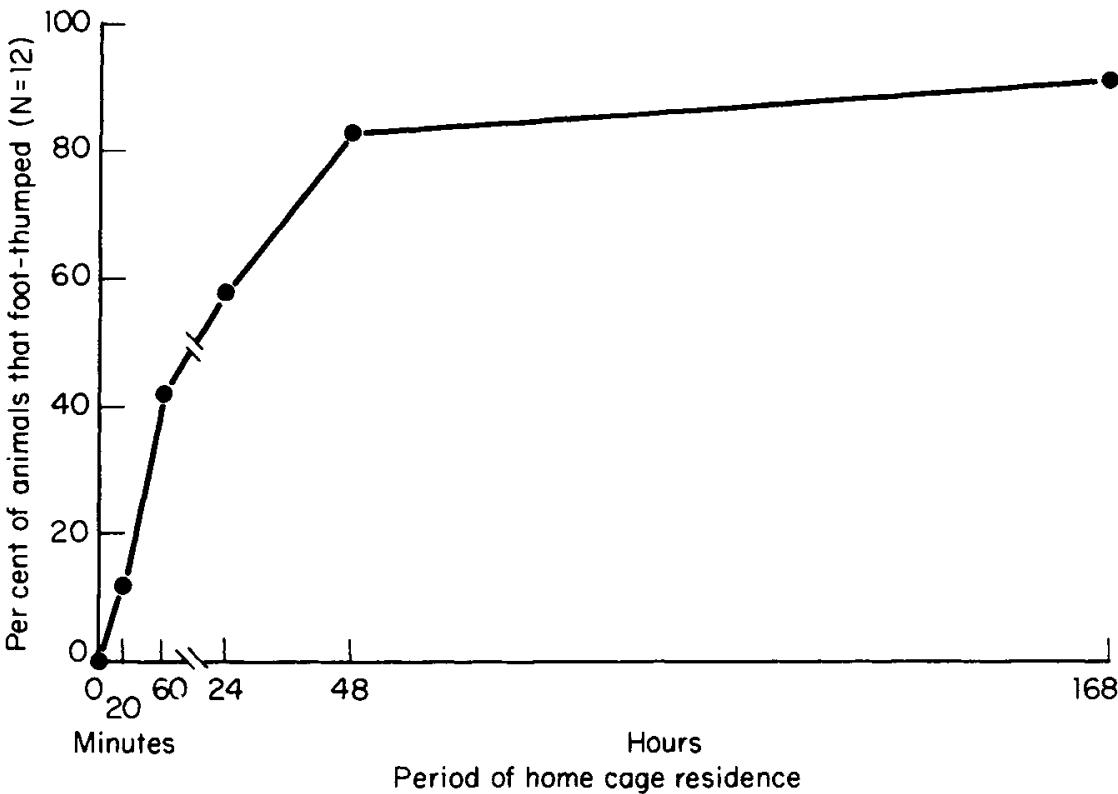

completed with 15 gerbils in which Ss were dropped into the vacant cage of another gerbil. These vacant cages had been occupied for 0,24 , or $168 \mathrm{~h}$ by an adult male gerbil. The cages and procedures were the same as those used in Experiments 1 and 2. Of the 15 gerbils, none foot-thumped when dropped in a fresh cage. Three Ss foot-thumped when dropped into a cage occupied for $24 \mathrm{~h}$ and three foot-thumped in the 168 -h condition.
The increase in the probability of foot-thumping seen in Experiments 1 and 2 was not seen in this experiment. In addition, a comparison of the number of gerbils that foot-thumped in their home cage (Experiments 1 and 2) with those that foot-thumped in another's cage showed that the two conditions differed significantly for the 168 -h condition, $\chi^{2}=14.97,1 \mathrm{df}, \mathrm{p}<.001$, using Yates' correction.
Fig. 1. Number of gerbils that foot-thumped after six periods of home cage residence, Experiment $1, N=12$.

This preliminary experiment is consistent with a territorial explanation of foot-thumping. Most territorial explanations, however, would require a demonstration that foot-thumping produced consistent responses in other gerbils. Other functional interpretations are also possible, e.g., a gerbil excited by the approach of a predator near his own burrow system may foot-thump, thus serving as a signal of danger to the rest of the colony.

\section{REFERENCES}

KRAMIS, R. C., \& ROUTTENBERG, A. Rewarding brain stimulation, hippocampal activity, and footstomping in the gerbil. Physiology \& Behavior, 1969, 4, 7-11.

KUEHN, R. E., \& ZUCKER, I. Reproductive behavior of the Mongolian gerbil (Meriones unguiculatus). Journal of Comparative \& Physiological Psychology, 1968, 66. 747-752. ROUTTENBERG, A., \& KRAMIS. R. C. 'Foot-stomping' in the gerbil: Rewarding brain stimulation, sexual behavior, and footshock. Nature, 1967, 214, 173-174. NOTES

1. This research was supported by NSF Grant GY 5665 and a grant from The University of the South. We wish to express our appreciation to Stephen E. Glickman for his valuable assistance with the manuscript.

2. Now at the University of Califomia Berkeley.

3. Now with the Peace Corps, Tonga Islands. 